\title{
Ethical standards for cardiothoracic surgeons' participation in social media
}

\author{
Thomas K. Varghese, Jr, MD, MS, ${ }^{a}$ John W. Entwistle III, MD, PhD, ${ }^{b}$ John E. Mayer, MD, \\ Susan D. Moffatt-Bruce, MD, PhD, MBA, ${ }^{\mathrm{d}}$ and Robert M. Sade, MD, ${ }^{\mathrm{e}}$ for the Cardiothoracic Ethics Forum*
}

\footnotetext{
From the ${ }^{\mathrm{a}}$ Division of Cardiothoracic Surgery, Department of Surgery, University of Utah, Salt Lake City, Utah; ${ }^{\mathrm{b}}$ Division of Cardiothoracic Surgery, Thomas Jefferson University, Philadelphia, Pa; ${ }^{\mathrm{C}}$ Department of Cardiac Surgery, Boston Children's Hospital, Boston, Mass; ' Division of Thoracic Surgery, Department of Surgery, The Ohio State University, Columbus, Ohio; and ${ }^{\mathrm{e}}$ Division of Cardiothoracic Surgery, Department of Surgery, Institute of Human Values in Health Care, Medical University of South Carolina, Charleston, SC.

Disclosures: Authors have nothing to disclose with regard to commercial support.

This article has been copublished in The Journal of Thoracic and Cardiovascular Surgery and The Annals of Thoracic Surgery.

* The following members of the Cardiothoracic Ethics Forum contributed to the writing of this article (the complete membership is listed at the end of the article): David Blitzer, MD, Andrea J. Carpenter, MD, Edward P. Chen, MD, Daniel H. Drake, MD, Kathleen N. Fenton, MD, Leslie Kohman, MD, Martin F. McKneally, MD, John D. Mitchell, MD, Sudish C. Murthy, MD, Shuddhadeb Ray, MD, Gregory D. Trachiotis, MD, and Richard I. Whyte, MD.

Address for reprints: Robert M. Sade, MD, Division of Cardiothoracic Surgery, University of South Carolina, 30

Courtenay Drive, MSC 295 Charleston, SC 29425-2950 (E-mail: sader@musc.edu).

J Thorac Cardiovasc Surg 2019;158:1139-43

$0022-5223 / \$ 36.00$

Copyright (C 2019 by The American Association for Thoracic Surgery and the Society of Thoracic Surgeons https://doi.org/10.1016/j.jtcvs.2019.03.029
}

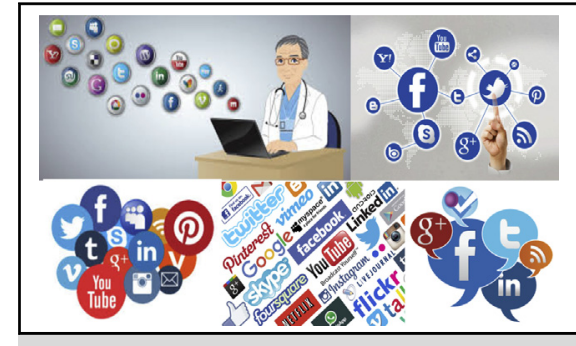

Many different platforms are available for communicating through social media.

\section{Central Message}

Surgeons using social media can benefit patients but also face possible violations of professionalism.
Human beings have evolved their modes of communication continually through the ages. Over the past decade, social media in their various forms have become the preferred mode among younger generations, and their use has increased among older generations as well. Worldwide users of social media are expected by 2021 to number more than 3 billion, which is approximately one third of the world's population. ${ }^{1}$ The region with the highest penetration rate of social networks is North America, wherein approximately $60 \%$ of the population has more than 1 social media account and $78 \%$ of the US population has a social networking profile. ${ }^{2}$

Social media offer enormous potential benefits for both care providers and patients, because the platform allows for the dissemination and gathering of information and has the innate ability to network globally. In fact, in a recent survey, $70 \%$ of surgeons indicated that they believe social media benefited professional development, whereas $22 \%$ preferred social media as their primary modality of networking and communication with colleagues. ${ }^{3}$

In using social media, care providers, particularly physicians and surgeons, must pay close attention to professionalism, specifically within the framework of professional ethics.

\section{BACKGROUND}

The Cardiothoracic (CT) Ethics Forum (the Forum) comprises the membership of the American Association for Thoracic Surgery (AATS) Ethics Committee and The Society of Thoracic Surgeons (STS) Standards and Ethics
Committee, as well as a few at-large members. The Forum functions as the ethics educational arm for the CT surgical community, producing ethics-related programs at major CT surgery meetings and subsequently publishing articles on those proceedings as well as ethical topics in CT surgical and other medical specialty journals. Among those articles are occasional policy statements for adoption by both the AATS and the STS; this report is such a policy statement, focusing on the use of social media by practicing CT surgeons and trainees in interprofessional communication and in the delivery of patient care.

The foundation for this review is targeted searches limited to English-language publications since 1990 in PubMed and MEDLINE databases using specific search terms: Medical Subject Heading terms "Social Media" and "Ethics OR Professionalism OR Ethics and Professionalism." We augmented the computerized literature search by manually reviewing the reference lists of identified studies and relevant reviews.

We identified 615 articles and abstracts; articles were excluded if data were duplicative, did not specify the use of social media, were purely descriptive, were opinion pieces, or were incomplete. Articles focusing on the use of social media by practicing physicians and surgeons were selected for detailed review. Additional Google searches were performed to evaluate nonmedical best practices and guidelines for professionalism in social media, specifically to assess for congruence (ie, to confirm reliability of recommendations due to the inherent nature of subjectivity in this field). Using information from this 
investigation, the Forum has constructed a set of recommendations for CT surgeons as they engage with social media.

\section{DEFINITIONS}

Social Media are computer-mediated technologies that facilitate interactions among virtual communities and networks, resulting in the creation and sharing of information, ideas, personal messages, and other forms of expression, such as videos. ${ }^{4}$ Although a variety of methodologies are available, common traits of social media include the use of interactive Internet-based applications, user-generated content, maintenance of user profiles through social media organizations, and facilitating social networks that connect users to other individuals or groups. For the most part, information published on social media platforms is not refereed or independently reviewed before posting.

Professionalism generally refers to the conduct, aims, or qualities that characterize a profession or professional individual. Although professionalism has been described in many ways, often including long lists of characteristics, it may perhaps be best understood as "the motivating force for an occupational group to come together and create, publicly profess, and develop reliable mechanisms to enforce shared promises-all with the purpose of ensuring that practitioners are worthy of patients' and the public's trust." ${ }^{5}$

The Codes of Ethics of the AATS and the STS are nearly identical and address a broad range of ethical concerns for CT surgeons. ${ }^{6,7}$ These codes generally reflect the principles of the Code of Medical Ethics of the American Medical Association, the oldest (dating from 1847 , with subsequent revisions) and most widely used ethical guidelines in the United States. The CT surgical society codes are useful in evaluating social media and providing guidelines for $\mathrm{CT}$ surgeons engaging with them. The following discussion also incorporates ideas from the American Medical Association ${ }^{8}$ and the American College of Physicians-American Society of Internal Medicine Foundation with the European Federation of Internal Medicine $^{9}$ analyses of professionalism in the use of social media.

\section{ETHICAL STANDARDS}

Standards for CT surgeons interacting with patients and other health professionals are provided by the AATS ${ }^{6}$ and $\mathrm{STS}^{7}$ codes of ethics, and these guidelines are fully applicable in the use of social media. Numbers in brackets below refer to item numbers common to both sets of guidelines. Some of the standards that are particularly pertinent to online interactions are as follows:

Patient Welfare Paramount: When caring for patients, surgeons must hold the patient's welfare paramount $\{1.1\}$, including providing care that maximizes anticipated benefits and minimizes potential harms. $\{1.4\}$ These guidelines apply equally in the digital world as in personal interactions.
Patient Autonomy: Physicians play a central role in the decision-making process by providing information so that patients can make informed decisions. $\{1.5\}$ Support for patient decisions should be the goal, as long as those decisions do not lead to inappropriate care. Digital technology and social media are particularly valuable because they can be used in providing generalized information for patients with similar conditions and the content can be durable. Patient-specific instructions can be conveyed electronically, but some information might be better delivered through direct interactions between the patient and surgeon. In addition to conveying information to allow the autonomous patient to agree voluntarily to a surgical procedure, the consent process has been found to involve an "entrustment" phenomenon in which the patient comes to gain confidence and to place trust in the operating surgeon. ${ }^{10}$ It is difficult to evaluate how social media interactions might affect this essential aspect of the patient-surgeon relationship, but it seems important to keep this consideration in mind when communicating online.

Confidentiality and Privacy: An important problem with all communications using social media is the potential for information to become publicly accessible. Protecting confidentiality (the obligation of the physician not to divulge patient information) and privacy (the right of patients to be free from intrusion into personal information or physical space) of patient-related information is more challenging than in high-security electronic medical records and in institutional databases. $\{1.6\}$ Some information may be best avoided within social media. Once in the public domain, patient information may be impossible to completely remove.

Honesty: Physicians are required to be honest with patients and colleagues. $\{1.9,2.2\}$ A special temptation of social media is exaggeration of a CT surgeon's skills and special expertise, which can be misleading or deceptive in violation of ethical obligations. $\{1.9\}$

Justice: This principle is often the most public of physician roles. Justice in the health care system includes the promotion of equitable distribution of resources $\{1.8\}$ and the elimination of discrimination $\{1.7\}$. Publicly defending patients' rights, especially in a wide-reaching social media universe, can be daunting, but is among the highest ideals of the medical profession.

\section{PROFESSIONAL COMMITMENTS}

Professional Discretion: Content posted to social media can be electronically captured at any time, even if the author deletes the original post. When individuals use private accounts or pseudonyms, it is not difficult to trace the origin of a posting in social media with digital technology. With this reality and consideration, CT surgeons should assume that any and all content can be ultimately traced to them, and consequently should post only valid and reliable 
materials that the author would be comfortable sharing with patients and professional colleagues. As a rule of thumb, nothing should be posted in social media that would not be said in a crowded elevator or cafeteria.

The use of pseudonyms on social media may obscure the identity of the person posting the information, making it difficult for a consumer of that information to assess the credentials of the poster and the validity of the information. Therefore, CT surgeons must strive to ensure that the information available to the consumers is accurate. $\{1.5,1.9\}$ When posting medically relevant information online that may be accessed by past, present, or future patients, CT surgeons must ensure that all pseudonyms allow ready identification of the surgeon.

CT surgeons must take responsibility for their online profiles by ensuring correct contact information and documentation of their scope of practice and competency on social media accounts for which they are directly or indirectly responsible. Indirect responsibility would include sites such as medical center accounts, but would exclude sites that have acquired their information secondarily, such as healthgrades.com and vitals.com. In addition, CT surgeons should work with professional organizations and medical centers in detailing accurate and timely information that can help in the care of their patients. Exaggerated institutional marketing claims about CT capabilities should be corrected. Embracing and enhancing one's digital presence can lead to positive interactions with patients, as long as the relationship is based on honest and accurate information.

Disclosure of Errors: Disclosure of errors often has legal consequences, so disclosures should be made in a timely and forthright fashion. Initially, in-person reporting to the patient is preferable to online discussion. Subsequent discussion can be continued online with the patient's consent, but may be fraught with danger for several reasons: Online posts are virtually indelible, and if new information comes to light that is inconsistent with or contrary to an initial post, it may not be shared with the social media community. Moreover, obtaining the patient's consent does not release the hospital, physician's colleagues, and any other associated individuals from potential blame or liability. If a CT surgeon wants to discuss health care errors on social media, the surgeon may be well advised to involve the legal consultants for their practices or hospitals before making such a posting.

Regardless of the context, however, reporting and analyzing errors should comply with established standards; that is, the standards of medical care do not change by virtue of the medium in which physicians and their patients choose to interact.

Patient Confidentiality and Privacy: CT surgeons often capture images and record videos for training, education, and quality-improvement purposes. Social media platforms facilitate posting these for widespread distribution.
However, CT surgeons must exercise caution and good judgment when posting on professional and personal accounts. $\{1.4,1.6\}$ If any personally identifiable information is included in the social media post, patient consent should be obtained in advance, with explicit details of what content will be posted, where it will be posted, and for what duration. Many health care organizations have explicit rules that require sanctions, including immediate dismissal for egregious breaches of patient confidentiality. Avoiding patient identifiers seems to be easy advice to follow, but the seamless ability to share information in real-time, for example, by copying material for posting, can lead to mistakes. One meta-analysis of physician blogs found that approximately $17 \%$ included enough information to permit identification of patients. ${ }^{11}$ Legally, sharing photographs or other forms of Protected Health Information, as defined under the Health Insurance Portability and Accountability Act, without the patient's consent is prohibited and carries severe penalties. ${ }^{12}$

Excluding personal feelings from professional conduct in an emotionally charged setting or situation can be difficult; expressing emotions publicly seems to be more prevalent than ever in the digital age. A deliberate pause and careful consideration before posting any content on social media can avoid publication of unsuitable material. Inappropriate postings can damage physician-patient relationships as well as reputations of individuals, health care entities, and our profession.

Maintaining Appropriate Relations With Patients: The ease of connecting with people all over the world by way of social media can also be a pitfall when interacting with patients. Most organizational guidelines advocate for the avoidance of online public interactions between physicians and their own patients during active care. ${ }^{13}$

CT surgeons should not use their professional position and influence to develop intimate relations with patients, either online or in person. In a survey of executive directors of state medical boards in the United States, $92 \%$ indicated that violations of online professionalism were reported in their district, including Internet use for inappropriate contact with patients, inappropriate prescribing, and misrepresentation of credentials or clinical outcomes. ${ }^{14}$

Patients may collect information about their surgeons with or without the surgeons' knowledge, such as recording conversations or taking photographs. Patients or others could publish such information on blogs or other social media. If surgeons become aware of inappropriate information published on social media in this way, they should request that the information be removed, and do so in a sensitive manner that avoids undermining patient relationships.

Scientific Knowledge: Among the powers of social media is the ability to collate large amounts of data, connect with people and entities globally, and establish relationships 
that can lead to collaborations and enhanced outcomes. One of the important potential benefits of social media is facilitation of information exchange among professional colleagues.

The great power of sharing content, however, imposes the responsibility of ensuring the accuracy of content. $\{1.5$, 6.1) The principles of science-hypothesis generation, testing, honest reporting of results, and transparent discussion in the context of limitations-must be upheld irrespective of the medium of communication. Constantly evolving commercial algorithms that produce user-specific advertising and highly personalized experiences may facilitate falling into silos of communication and homogenization of thought. CT surgeons must uphold scientific standards, promote research, and ensure responsible integration of evidence-based knowledge in practice.

CT surgeons must avoid the temptation to alter the care of the patient to generate material for posting on social media. For instance, a procedure should not be changed or substantially delayed to produce a photograph or other material for posting a description of a surgical innovation.

Research: As much as $60 \%$ of clinical and translational investigations are delayed or cannot be completed because of insufficient enrollment; for this reason, efforts to recruit subjects for research have increased in recent years. ${ }^{15}$ When recruiting through social media, investigators must be cognizant of several ethically relevant issues. As a matter of respect for potential research subjects, transparency is critically important, meaning that descriptions of research protocols must be honest and accurate. Transparency also requires that researchers make their presence known on media in which they are searching for potential recruits-lurking is not acceptable. ${ }^{15}$

Ethical problems may be related to recruiting patients to research projects involving rare conditions or small patient populations. Patients interested in becoming research subjects may be vulnerable because they have diseases that are rare or are not readily treated with standard medicine or procedures. Approximately $8 \%$ of patients who are involved in medical research found the trials in which they are enrolled by searching social media. ${ }^{16}$ Social media posts have the potential to be misleading, so CT surgeons should carefully avoid posting statements that may mislead vulnerable patients. The use of social media as a recruiting tool should be disclosed to the Institutional Review Board overseeing the study to ensure appropriate oversight, as required by the new Common Rule. ${ }^{17}$

Maintaining Trust by Managing Conflicts of Interests: When CT surgeons post online about their experiences and their commercial relations, medical credentials should be honestly reported and conflicts of interest should be properly disclosed. ${ }^{18}\{8.3\}$ Incorrect information and false accounts abound on the Internet, but are inexcusable in the context of patient care.
Professionalism: A recent systematic review published by the American College of Surgeons Resident and Associate Society identified 7 sets of guidelines on the use of social media developed by medical professional organizations. ${ }^{19}$ Common themes across the guidelines included the utility of easy dissemination of information using social media platforms, consideration of separating personal and professional content through separate accounts, monitoring of personal and professional information online, and awareness of social media policies set by employers and practices. Whether or not to establish separate professional and personal accounts is a complex question. A separate account that is intended to be only personal has the advantage of a degree of privacy, but anything posted, even in an apparently private account, has the potential to become public, and the maintenance of multiple accounts can be cumbersome.

The structure of social media lends itself to be used as a format for healthy public debate. With the relative anonymity that social media offer (compared with a national meeting) and the rapid response time (compared with comments submitted to a journal), a lively debate can easily devolve into a public squabble with insults and innuendos. It is critical that surgeons who engage in debate through social media maintain a professional demeanor, because inappropriate comments can reflect poorly not only on the person who posts the message but also on our profession as a whole.

Professionalism also obligates physicians to take action when they see unprofessional content posted by another physician online, by bringing the transgression to the attention of the individual so it can be corrected, and if not corrected, to the attention of appropriate authorities. ${ }^{8}\{2.4\}$

\section{ETHICAL STANDARDS FOR CARDIOTHORACIC SURGEONS USING SOCIAL MEDIA}

The ease of use, the ability to connect globally in realtime and asynchronously, and the increasing popularity of social media promise benefits but also pose dangers in caring for patients. Reaffirming the principles of professionalism in the digital era entails both a personal commitment to professional standards and collective efforts by specialties such as CT surgery, including its trainees, and the medical profession as a whole, aiming to benefit individual patients and society.

1. CT surgeons must be guided by the foundational principle of medical ethics-holding the welfare of the patient as paramount-in all interactions, in person and online.

2. Protecting patient confidentiality and privacy in all communication environments requires surgeons to be sensitive and vigilant.

3. All posted information should be considered permanent, even when modified or deleted. 
4. CT surgeons are responsible for the accuracy of all electronic content relating to their personal and professional activities that they disseminate or have disseminated on their behalf, including information about them posted by their employers. They are also responsible for actively monitoring electronic content relating to their personal and professional activities that is disseminated by third parties without their involvement, and for taking prompt action to correct false, misleading, or other inappropriate content about which they subsequently become aware.

5. When interacting with patients online, CT surgeons must maintain appropriate personal and professional boundaries.

6. CT surgeons should not use unprofessional language such as insults and innuendos when engaging in public discussion or debate on social media.

7. When unprofessional content is posted by other health professionals, CT surgeons should approach that individual regarding the content in question and request corrective action. If such action is requested and not taken, the CT surgeon should report the unprofessional behavior to the appropriate supervisory or governing entity and professional society.

8. When a medical error has occurred, the CT surgeon is obligated to disclose the relevant information in person to the patient or patient's representative; additional discussion online should be strongly discouraged and carried out only with the patient's consent and appropriate legal safeguards.

9. The use of pseudonyms is acceptable when durable medical information is posted online, only when such use is not misleading or deceptive; CT surgeons must ensure that pseudonyms readily allow identification of the surgeon when posting medically relevant information online that may be accessed by past, present, or future patients.

10. Physicians using social media to recruit for medical research projects must take precautions and adhere to Institutional Review Board stipulations to ensure the protection of vulnerable patient populations.

Members of the Cardiothoracic Ethics Forum: David Blitzer, MD, Charles C. Canver, MD, Andrea J. Carpenter, MD, Edward P. Chen, MD, Ralph J. Damiano, MD, Thomas A. D'Amico, MD, Daniel H. Drake, MD, Jennifer L. Ellis, MD, JohnW. Entwistle III, MD, PhD, Kathleen N. Fenton, MD, Richard K. Freeman, MD, James Jaggers, MD, Leslie Kohman, MD, James Jones, MD, John E. Mayer, MD, Martin F. McKneally, MD, Scott J. Millikan, MD, John D. Mitchell, MD, Scott Mitchell, MD, Susan D. Moffatt-Bruce, MD, PhD, MBA, Sudish C. Murthy, MD, Mark B. Orringer, MD, Allan Pickens, MD, Shuddhadeb Ray, MD, Robert M. Sade, MD (Chair), Sandra L. Starnes, MD, Gregory D.
Trachiotis, MD, Richard I. Whyte, MD, Douglas E. Wood, MD, and Joseph B. Zwischenberger, MD. Dr Sade's role in this publication was supported by the South Carolina Clinical and Translational Research Institute, Medical University of South Carolina's Clinical and Translational Science Award Number UL1TR001450. The contents are solely the responsibility of the authors and do not necessarily represent the official views of the National Center for Advancing Translational Science of the National Institutes of Health.

\section{References}

1. Statista. Number of social media users worldwide from 2010 to 2021 . The statistical portal. Available at: https://www.statista.com/statistics/278414/number-ofworldwide-social-network-users/. Accessed January 17, 2018

2. Pew Research Center. Social media fact sheet. Available at: http://www. pewinternet.org/fact-sheet/social-media/. Accessed January 17, 2018.

3. Wagner JP, Cochran AL, Jones C, Gusani NJ, Varghese TK Jr, Attai DJ. Professional use of social media among surgeons: results of a multi-institutional study. J Surg Educ. 2018;75:804-10.

4. Wikipedia.org. Social media definition. Available at: https://en.wikipedia.org/ wiki/Social_media. Accessed January 17, 2018.

5. Wynia MK, Papadakis MA, Sullivan WM, Hafferty FW. More than a list of values and desired behaviors: a foundational understanding of medical professionalism. Acad Med. 2014;89:712-4.

6. American Association for Thoracic Surgery. Code of ethics. Available at: http:// aats.org/aatsimis/aats/association/by-laws_and_policies/code_of_ethics/code_ of_ethics.aspx?websitekey=81f79f5f-4a27-4146-913d-cffea0ac81f7. Accessed January 17, 2018.

7. Society of Thoracic Surgeons. Code of ethics. Available at: http://sts.org/aboutsts/policies/code-ethics. Accessed January 17, 2018.

8. Council on Ethical and Judicial Affairs, American Medical Association. Professionalism in the use of social media. CEJA Report 8-I-10. Available at: https:/ www.ama-assn.org/sites/default/files/media-browser/public/about-ama/councils /Council\%20Reports/council-on-ethics-and-judicial-affairs/i10-ceja-profession alism-use-social-media.pdf. Accessed January 17, 2018.

9. ABIM Foundation, ACP-ASIM Foundation, European Federation of Internal Medicine. Medical professionalism in the new millennium: a physician charter. Ann Intern Med. 2002;136:243-6.

10. McKneally MF, Martin DF. An entrustment model of consent for surgical treatment of life-threatening illness: perspective of patients requiring esophagectomy J Thorac Cardiovasc Surg. 2000;120:264-9.

11. Lagu T, Kaufman EJ, Asch DA, Armstrong K. Content of weblogs written by health professionals. J Gen Intern Med. 2008;23:1642-6.

12. US Department of Health and Human Services, Office of Civil Rights. Summary of the HIPAA privacy rule. Available at: https://www.hhs.gov/sites/default/files/ privacysummary.pdf. Accessed January 17, 2018.

13. Federation of State Medical Boards Special Committee on Ethics and Professionalism. Model policy guidelines for the appropriate use of social media and social networking in medical practice. Available at: https://www.fsmb.org/Media/ Default/PDF/FSMB/Advocacy/pub-social-media-guidelines.pdf. Accessed January $17,2017$.

14. Greysen SR, Johnson D, Kind T, Chretien KC, Gross CP, Young A, et al. Online professionalism investigations by state medical boards: first, do no harm. Ann Intern Med. 2013;158:124-30.

15. Gelinas L, Pierce R, Winkler S, Cohen IG, Lynch HF, Bierer BE. Using social media as a research recruitment tool: ethical issues and recommendations. Am J Bioeth. 2017;17:3-14.

16. CenterWatch. How do patients find clinical trials? Available at: https://www. centerwatch.com/images/infographics/how-patients-find-clinical-trials.png. Accessed January 17, 2018.

17. 82 Federal Register 7149-7274 (January 19, 2017). Available at: https://www gpo.gov/fdsys/pkg/FR-2017-01-19/html/2017-01058.htm. Accessed January $17,2018$.

18. Mack MJ, Sade RM. Relations between cardiothoracic surgeons and industry Ann Thorac Surg. 2009;87:1334-6.

19. Logghe HJ, Boeck MA, Gusani N, Hardaway JC, Hughes KA, Mouawad NJ et al. Best practices for surgeons' social media use: statement of the Resident and Associate Society of the American College of Surgeons. J Am Coll Surg. 2018;226:317-27. 